\title{
Social Inequalities and the Effects of Incentives on Survey Participation: A Recruitment Experiment
}

\author{
Alexander Seymer ${ }^{1, *} \&$ Martin Weichbold ${ }^{1}$ \\ 1 Department of Sociology, University of Salzburg, Austria \\ * Alexander.Seymer@sbg.ac.at.
}

\begin{abstract}
Incentives are often discussed in the literature on the topic as a way to increase response rates. In this article, sample composition and item nonresponse are also considered. Using social exchange theory, the concept of social inequality is theoretically linked to the effect of incentives and is empirically tested using data from a recruitment experiment for an online survey in Austria. Since the participants of the Austrian micro-census were used as the selection framework, a detailed analysis of nonresponse is possible. Based on the four different incentives (a brochure, a $€ 2$ commemorative coin, a $€ 5$ commemorative coin and a $€$ IO voucher), conclusions can be drawn about the different forms incentives take and the values they hold. The results underline the potential of incentives to increase response rates, but at the same time they reveal potential distortion problems.
\end{abstract}

\section{Keywords}

Nonresponse, Incentives, Response Rate, Web Survey, Sampling Experiment, Social Exchange Theory

\section{Soziale Ungleichheit und der Einfluss von Incentives auf die Teilnahme an Webumfragen: Ein Rekrutierungsexperiment}

\section{Zusammenfassung}

In der Literatur werden Incentives häufig als Möglichkeit zur Erhöhung der Ausschöpfung diskutiert. In diesem Artikel werden neben der Ausschöpfung auch die Stichprobenzusammensetzung und der Item-Non-Response betrachtet. In Anlehnung an die soziale Austauschtheorie wird das Konzept der sozialen Ungleichheit mit der Wirkung von Incentives theoretisch verknüpft und empirisch anhand der Daten eines Rekrutierungsexperiments für eine Onlinebefragung in Österreich getestet. Da als Auswahlrahmen die TeilnehmerInnen des österreichischen Mikrozensus verwendet wurde, ist eine detaillierte Analyse des Nonresponse möglich. Basierend auf den vier unterschiedlichen Incentives (Broschüre, €2 Gedenkmünze, $€ 5$ Gedenkmünze und $€$ IO Gutschein) können Schlussfolgerungen über die verschiedenen Formen und Höhen der Incentives abgeleitet werden. Die Ergebnisse unterstreichen das Potential von Incentives zur Erhöhung der Ausschöpfung, zeigen aber gleichzeitig auch potentielle Verzerrungsprobleme auf.

\section{Schlüsselwörter}

Nonresponse, Incentives, Ausschöpfung, Onlinebefragung, Rekrutierungexperiment, Soziale Austauschtheorie

\section{Acknowledgements}

We thank Matthias Till and Statistics Austria for assistance with the data and answering our inquiries for sampling procedures patiently, and the two anonymous reviewers for their detailed comments that greatly improved the manuscript.

The authors have declared that no competing interests exist. 


\section{Introduction}

Over the past few decades, survey researchers have encountered a decline in response rates, which has led to a demand for additional efforts to ensure survey quality (Bethlehem et al. 20II; 20I4). Amongst the different theoretical explanations for survey participation, the two most prominent are social exchange theory (Dillman et al. 20I4) and the leverage-salience model (Groves et al. 2009; 2000). Both approaches focus on actor-orientated explanations for survey participation but leave out structural arguments. Consequently, most of the literature on incentives focuses primarily on their impact on response rates (see, for example, Scherpenzel/Toepoel 20I2; Göritz 2006), while the theoretical models for explaining incentive effects have gained less attention (Kennedy/Ouimet 20I4). Despite a number of efforts, incentives only increase the overall response rates slightly, and alternative measures seem to be more effective (such as multiple reminders or combining survey modes; see Messer/Dillman 20II; Converse et al. 2008; De Leeuw et al. 2007) when they support what Dillman et al. (2014) call 'the tailored design method', which implements the most successful combination of these measures for the specific survey design.

As response rates alone are insufficient to measure survey quality (Groves 2006; Singer/Ye 20I3), nonresponse bias has received more attention in recent years (Pforr et al. 20I5; Schupp/Wolf 20I5; Felderer et al. 20I7). In the following sections of this article, we will contribute to debates on nonresponse bias by examining the effects of four different incentives, namely a symbolic brochure, a $€ 2$ commemorative coin, a $€ 5$ commemorative coin and a $€$ Io voucher, on response rates, sample composition and item nonresponse. More specifically, the association between incentive effects and social inequalities will be addressed, as we argue that nonresponse and the effects of incentives on sample composition relate to socio-structural characteristics. If web surveys are biased in their composition towards subpopulations in society, the conclusions drawn from these surveys need to be considered accordingly. Therefore, the results have important implications, beyond academic debates, for the application of web surveys.

While most studies only contain information about survey respondents (but very little about nonrespondents), our recruiting experiment was based on an Austrian micro-census sample from 20I6, which gives us rich information about all the people in the sampling frame, and therefore allows for detailed analyses.

We begin with a discussion about the theoretical connections between survey participation and social inequalities. The empirical analysis is introduced with a description of the recruitment experiment and the impact of the recruitment process across the four different incentives (brochure, $€ 2$ token, $€ 5$ token and $€$ IO voucher). After this, we compare incentive groups according to key indicators of socio-structural position. With a logistic regression for the unit nonresponse and a Poisson regression for item nonresponse, we consolidate the findings by introducing control variables. The results indicate that socio-structural position has a clear impact on incentive effects and survey participation, in more general terms. These effects can be proven through response rate differences and distorted sample compositions. Both these results suggest that a thorough consideration of survey recruitment procedures is needed in times of generally declining survey participation rates.

\section{Theoretical Background}

It might seem obvious to link incentives and social inequality, but most survey participation research takes an actor-centred approach that focuses more closely on survey, recruitment and individual-level characteristics rather than on social structure. According to the framework of social exchange theory (Dillman et al. 20I4, $27 \mathrm{ff}$.), a survey researcher should decrease costs (such as by reducing length and complexity, making it more convenient to respond or minimising requests for sensitive information), increase benefits (such as by communicating how the results will be used, conveying that others have responded or using legitimate and trusted sponsors) and establish trust (such as by giving assurance that responses will be confidential and data will be protected, using a professional design or providing a token of appreciation). Groves et al. (2009, 20Iff.) take a different perspective and argue that intrinsic motivations for survey participation can be replaced by extrinsic stimuli, such as incentives. These two dominant theoretical arguments for survey participation primarily address the interaction between respondent and survey. Consequently, the literature on incentives needs to be supplemented with a concept for differentiating social structure. After introducing incentives and social structure conceptually, both will be incorporated into a set of hypotheses.

\subsection{Incentives}

Incentives can be differentiated according to the timing of the delivery and the form of the incentive (Church 1993). In relation to timing, incentives can be either unconditional or conditional. Unconditional incentives are offered upfront and do not require participation in the survey. The delivery of conditional incentives depends on partial or full participation in the survey. The 
manifold forms of incentives can be roughly divided into monetary and non-monetary categories. ${ }^{1}$ Monetary incentives are either handed over directly as cash or indirectly as cheques and vouchers. Non-monetary incentives are all alternative forms of remuneration, which can range from simple gifts (books, pens and so on) to lottery tickets and donations made on behalf of the respondent (Stähli/Joye 2016, 426). The main difference between monetary and non-monetary incentives is direct usability for the addressee. While monetary incentives can be invested to meet individual needs, nonmonetary incentives make a predefined and fixed offer with a different benefit for each addressee. In a nutshell, monetary incentives work better than non-monetary incentives, and unconditional incentives work better than conditional ones (Stähli/Joye 20I6, 429).

Beyond their definition, incentives are part of general theoretical research on explaining and improving survey participation. The two most prominent micro-level approaches to incentive effects are based on economic exchange and social exchange theories (Stähli/Joye, 2016). According to economic exchange theory, individuals carry out a cost-benefit calculation (Singer 20II), and, accordingly, higher incentives should increase willingness to participate. The linear association between participation and the amount of incentive is only partially supported through high-value incentives, while an explanation is still lacking for the mechanism behind small incentives. Social exchange theory (Dillman et al. 2014) brings in the idea of reciprocity, arguing that social interaction itself is the reward and incentives serve as triggers for interaction, as participating in a survey offers something in return. Therefore, the amount is not decisive, but rather the initiative.

Groves et al. (1992; 2000; 2009) developed a psychological approach called the leverage-salience model that enhanced previous theoretical explanations. Six principles of compliance with requests (reciprocation, consistency, social validation, authority, scarcity and liking) are weighted differently for each individual and thus form the basis for deciding to participate in a survey. Groves et al. (1992) consider the model to be a supplement to other explanatory models focusing on the interaction between respondents and the survey instrument or interviewer.

The theory of social exchange for incentive effects is confirmed in many studies by the effectiveness of prepaid incentives (see, for example, Singer/Ye 20I3; Pforr et al. 2015). Prepaid incentives increase response rates for longitudinal surveys (Laurie/Lynn 2009), web surveys (Göritz 2006), telephone surveys (Medway/Tou-

I This dichotomisation is a simplified organisation of forms of incentives, which covers the relevant concepts for this research. (For a detailed overview, see Ernst Stähli and Joye, 20I6.) rangeau 20I5) and face-to-face interviews (Pforr et al. 2015; Grauenhorst et al. 2015; Blohm/Koch 2013), but at the same time some results are ambiguous in this area (Medway/Tourangeau 2015; Scherpenzel/Toepoel 2012) or show that prepaid incentives only have a slight impact on response rates (Kennedy/Quimet 20I4). In all these studies, sample composition is rarely analysed, and results relating to incentive effects on sample composition are inconclusive (Medway/Tourangeau 2015; Petrolia/Bhattacharjee 2009). We think that this is a gap in the research and argue that social exchange is linked to socio-structural position (Bourdieu 1979, 1986).

\subsection{Social inequality}

To return to social structure, it can be differentiated horizontally or vertically. At least four different models can be identified in current debates (Geißler 20I4): social classes and strata/layers, social positions, social milieus and lifestyles, and exclusion and inclusion. Social classes and strata are not defined in a uniform way by focusing on the vertical differentiation of socioeconomic positions into homogeneous classes or strata. While layer models (Dahrendorf 1968) tend to have a descriptive character, class models (see, for example, the EGP scale by Erikson et al. 20I0) have their theoretical basis in the consideration of conflict and power relations, as well as historical developments (Wright 2005). Social class and layer models are primarily hierarchical ways of making a fine-grained distinction between upper, middle and lower spaces in the social structure. Since layer models do not depict vertical inequalities, the concept of social positions emerged, which included horizontal indicators such as gender, age or geographical region. The combination of these characteristics results in a more detailed pattern of social structures (Habich 20II; Bünning 20I6). Social milieus and lifestyles focus on subjective location in the social structure by combining value orientations or consumption patterns with classical vertical characterisations of social structure (Hradil 2012). Finally, exclusion and inclusion models emerged from analyses of socially excluded people in social policy contexts and are strongly oriented towards concepts of poverty, unemployment and spatial segregation (Kronauer 2008). These models attempt to identify criteria for social exclusion, instead of characterising the entire population. In addition to these four paradigms, some authors combine different models, such as Vester et al. (200I), who bring together class- and milieu-based approaches. All models differentiate social structure according to different theoretical arguments, but three core indicators are commonly used for their operationalisation: occupation, education and income. As this article is concerned with incentive effects on nonresponse, rather than providing 
evidence for theoretical models of social structure, we will focus on the association between these three indicators and the different impact of incentives as regards social inequality.

\subsection{Linking incentives and social inequality}

Previous research has indicated that nonresponse in surveys is dependent on socioeconomic status (see, for example, Warringer/Miller 2002; Couper et al. 2007). We argue that people with higher socioeconomic status have more positive experiences of social exchange on a dayto-day basis, which leads them to have higher degrees of social trust. Lawler (200I) argues through his affect theory of social exchange that the emotions produced by social exchange strengthen or weaken ties to groups or networks. Furthermore, social exchange requires trust that expectations in interaction and exchange will be fulfilled. Molm et al. (2007) developed a theory of reciprocity in exchange, which asserted the importance of generalised indirect exchange for the emergence of solidarity. Consequently, the experience of social exchange as a result of socio-structural position should influence levels of trust in social exchange in general and also in incentives. By measuring social position according to occupation, education and income, several hypotheses can be derived:

H1: refers to the influence of education. The literature in this area provides inconclusive evidence for the effect of education, as some studies support such an association (see, for example, Pforr et al. 2015), others find no significant effect (see, for example, Blohm/Koch 2013), while in some studies education was introduced as a control variable without specifying the respective effect size and significance (see, for example, Grauenhorst et al. 2015). According to concepts of social inequality (Bourdieu 1986), people with higher-education degrees have more positive experiences during their time in the education system, which manifests in them achieving higher degrees. Consequently, we expect that (a) people with higher education are more likely to respond to symbolic incentives, i.e. non-monetary or monetary incentives of very low monetary value, than people with a lower level of education. Considered the other way around, one should have most difficulty in recruiting people with lower education levels, despite offering them incentives, as such people are less likely to enter social exchange due to previous experiences (Lawler 2001; Molm et al. 2007). Despite the general difference in incentive effects between people with higher and lower levels of education, we expect that (b) the difference between the education groups will be smaller for higher-value incentives in comparison to low-value or symbolic incentives.
H2: In terms of income, we argue that social exchange is the driving force behind incentives effects, and thus we expect that (a) higher-income groups are more likely to respond to all incentives, as monetary incentives' utility decreases relative to the income of the responder, which makes all incentives merely symbolic ones for high-income groups. For people with lower incomes, we expect to find (b) higher levels of response to monetary incentives and a smaller effect of symbolic incentives when compared to higher-income groups. Regarding the available data, this distinction between monetary and non-monetary incentives will be difficult to identify for the two tokens, which are monetary in the form of normal cash and symbolic in the form of collector items simultaneously.

H3: Within the context of occupational status, the effect of incentives can be deduced from the reciprocity theory of social exchange (Molm et al. 2007). Since (a) workers have, due to their weaker negotiation power, fewer positive experiences with social exchange, they should be less motivated by incentives. Symbolic incentives in particular should lead to lower response rates in comparison with other groups. (b) Pensioners are difficult to classify within models of social inequality but are becoming an increasingly prominent group in aging societies. While a successful career can ensure a very good quality of life in old age, other pensioners are affected by old-age poverty. ${ }^{2}$ Despite socioeconomic differences, pensioners share a common feature that has particular relevance for social exchange: the number of social contacts an individual has decreases after leaving the labour market, and elderly people are more likely to be affected by loneliness and social isolation (see, for example, de Jong Gierveld et al. 2016). For these reasons, we expect pensioners to react more positively to incentives, especially prepaid incentives as tokens of appreciation, as pensioners are keener to enter into social interaction.

The hypotheses are tested out on the results of a recruitment experiment for a web survey in Austria in 2016.

\section{Data and Methods}

We use a data set from a recruiting experiment, which includes a web survey carried out by Statistics Austria on behalf of the Austrian Platform for Surveys, Methods and Empirical Analyses (PUMA) in 2016. The experiment intended to identify an optimal recruitment

2 A possible operationalisation would be to characterise pensioners according to their previous professional activity. 
procedure for a planned online panel in Austria. As a sampling frame, a subsample of the Austrian microcensus was used. The micro-census is part of official statistics; it is a quarterly household survey of about 22,500 Austrian households, including approximately 40,000 people whose participation was obligatory. The sample is stratified according to federal state and uses disproportionate selection to ensure that smaller federal states are sufficiently represented. In the private households that were selected, all persons aged 15 and over are interviewed. The sampling model has a rotational design. Each selected household is interviewed five times before leaving the micro-census, so one fifth of the sample is replaced every quarter (for details see Kytir/Stadler 2004; Haslinger/Kytir 2006).

For the experiment, persons who participated for the final time in the second quarter of 2016 and were aged between 16 and 74 served as the sampling frame, which comprised 6,388 people. For methodological reasons, we restricted the frame to persons with a valid telephone number and sufficient German-language skills. As a result, the final sampling frame of this experiment consists of 4,249 people including 342 non-Austrian citizens aged between 16 and $74 .^{3}$ Their previous participation in the micro-census survey provides us with rich information about sociodemographic and other characteristics for the participants in our recruitment experiment, as well as for non-respondents.

At the end of their final micro-census interview, all people were asked to participate in the web survey:

"Finally, the Federal Institute for Statistics Austria would like to ask you to help us by completing a web survey for Austrian universities. It is about exciting topics, which strongly affect the quality of life of all people in Austria (such as health and provision for old age)."

The introduction was followed by one of four different texts that offered different incentives, which were randomly assigned to each respondent:

I. "As a small thank you, Statistics Austria wishes to present you with the latest issue of Facts and Figures, a paperback book on the living conditions of people in Austria. Would you be willing to take part in this internet survey?" (Brochure group.)

2. "As a small thank you, Statistics Austria wishes to give you the current $€ 2$ token coin of the Austrian National Bank for collecting or issuing. Would you be willing to take part in this internet survey?" (€2 token group.)

3. "As a small thank you, Statistics Austria wishes to give you the current $€ 5$ token coin featuring Albrecht Dürer's field hare for collecting or issuing. Would you be willing to take part in this internet survey?" $\left(€_{5}\right.$ token group.)

4. "As a small thank you, Statistics Austria wishes to give you a voucher worth $€$ IO, which you can redeem almost anywhere in Austria, such as in grocery stores. Would you be willing to take part in this internet survey?" (Voucher group.)

The respondents were provided with five response options:

a) Yes, I'll participate (internet access available).

b) Yes, perhaps (please send me more information).

Table 1: Response to CATI-based recruitment attempts

\begin{tabular}{|c|c|c|c|c|c|}
\hline & Brochure & $€ 2$ token & $€ 5$ token & Voucher & Total \\
\hline $\begin{array}{l}\text { Yes, I'll participate (Internet } \\
\text { access available) }\end{array}$ & $332(29.8 \%)$ & $371(35.5 \%)$ & $409(38.7 \%)$ & $394(38.2 \%)$ & $1,506(35.4 \%)$ \\
\hline $\begin{array}{l}\text { Yes, perhaps (please send me } \\
\text { more information) }\end{array}$ & $12(1.1 \%)$ & $12(1.1 \%)$ & $10(0.9 \%)$ & $8(0.8 \%)$ & $42(1.0 \%)$ \\
\hline Overall number recruited & $344(30.9 \%)$ & $383(36.6 \%)$ & $419(39.7 \%)$ & $402(39.0 \%)$ & $1.548(36.4 \%)$ \\
\hline $\begin{array}{l}\text { Yes, I'm essentially interested, } \\
\text { but I have no Internet access }\end{array}$ & $24(2.2 \%)$ & $30(2.9 \%)$ & $32(3.0 \%)$ & $27(2.6 \%)$ & $113(2.7 \%)$ \\
\hline $\begin{array}{l}\text { No, I cannot participate for other } \\
\text { reasons (e.g. language skills) }\end{array}$ & $20(1.8 \%)$ & $30(2.9 \%)$ & $17(1.6 \%)$ & $25(2.4 \%)$ & $92(2.2 \%)$ \\
\hline No, I'm not interested & $727(65.2 \%)$ & $603(57.6 \%)$ & $588(55.7 \%)$ & $578(56.0 \%)$ & $2,496(58.7 \%)$ \\
\hline Total & $1,115(100.0 \%)$ & $1,046(100.0 \%)$ & $1,056(100.0 \%)$ & $1,032(100.0 \%)$ & $4,249(100.0 \%)$ \\
\hline
\end{tabular}

$X^{2}=202.669, d f=15, p=0.000$

3 The selection of respondents for telephone recruitment distorted the otherwise very representative sample of 6,388 people (Seymer 2017). 
c) Yes, I'm essentially interested, but I don't have Internet access.

d) No, I cannot participate for other reasons (such as German-language skills).

e) No, I'm not interested.

All persons who responded with category a) or b) received a letter in the post, which invited them to participate by using the access code to the web survey, and the corresponding incentive, within ten days. Two weeks after the invitation letter, a reminder postcard was sent out to all people; for those who provided an email address, an additional reminder with an electronic version of the invitation or reminder was sent out via email two days later. Furthermore, the respondents were provided with a telephone hotline for queries.

The web questionnaire contained more than Ioo items, but each respondent was asked only a selection of all the questions based on filter questions. The filter questions ascertained professional activity (yes or no), whether the person had already been employed (yes or no) and whether the person was retired. Using this filter, questions on: health issues and work-life balance; work, age and retirement; visions of the future and financial problems; age and felt age; tax issues and sociodemographic characteristics were posed to respondents. All persons that failed to provide 15 or more answers were excluded from the survey, and 2.7 per cent (n=II3) lacked internet access, although these people had expressed their interest (see Table I).

As the experiment only included prepaid incentives, we compare the brochure group against the other groups by analysing differences between non-cash and monetary incentives, while the distinction between the token groups and the voucher group allows for a further differentiation between quasi-monetary and monetary incentives. The voucher was a shopping voucher, which could be redeemed in many shops, but it is less transferable than cash, and so this influences the incentive effect. For this reason, only the two token groups can be used to compare the incentive value, since only the monetary value differs for these two groups. As a result, the analysis focuses on three comparisons: non-objective incentive versus cash incentive; voucher versus cash incentive; and $€ 2$ versus $€ 5$ token.

The unit nonresponse is defined as the ratio of valid questionnaires to the sample frame addressed by the telephone recruitment effort. Unit nonresponse can be divided into different points at which 'dropout' occurs: at the stage of the telephone contact; after receiving the prepaid incentive and never attempting to participate; and due to item nonresponse on more than I 4 items. All three types are equally considered as forms of nonresponse in the later analysis. Only Table I provides details about the different stages in the recruitment process. Item nonresponse is operationalised as a count variable with a minimum of zero missing items and a maximum of 14 missing items.

Income was captured in the online survey as monthly personal gross income across 15 categories ranging from below 250 EUR to more than 6,000 EUR. For this analysis, the scale has been divided up into four categories: up to I,300 EUR; I,30I to 2,500 EUR; 2,50I EUR to 4,ooo EUR; and more than 4.00o EUR to provide meaningful categories on sample composition. As the variable is part of the web survey, the information is unavailable for nonresponse. For the nonresponse analysis, the income quintiles provided by the micro-census are used. ${ }^{4}$ Occupation is recoded from multiple micro-census questions that capture employment status and job position to identify groups that are actively involved in the labour market (as a clerk, worker, civil servant, contract agent or self-employed worker) and those that are inactive (pensioner, unemployed). Education was measured in the micro-census on a scale with II categories ranging from no compulsory schooling to doctorate. For the analysis, the scale was collapsed into the categories of maximum compulsory schooling, apprenticeship, vocational or commercial school, Matura (or high-school equivalent, such as the UK A level), university degree and alternative higher degree after the Matura. Table 2 gives the distributions of the three indicators in the sampling frame.

First, different incentives are examined according to their effect on the distribution of the three indicators (occupation, education, income) within the sample that is recruited. We rely on cross-tabulations and chi-square difference tests to identify bivariate relationships and to describe the sample in general. Second, the three indicators are assessed in a logistic regression model for the unit response rates. For the logistic regression model, control variables are introduced to analyse the relevance of multivariate socio-structural characteristics. Third, the item nonresponse across the incentive groups is compared with the Poisson regression, which includes the same independent variables as the model on unit response rates. All analysis has been carried out with $\mathrm{R}$ 3.4.O, and for the regression models the glm function from the stats package was used (R Core Team 20I8). ${ }^{5}$

4 The micro-census provided only income quintiles, which are more difficult to compare across groups as the intervals vary. Hence, the data.

5 Supplementary files are available at https://www.seymer.at/publication/oezp-20I8/. 


\section{Results}

While the hypotheses are structured according to sociostructural characteristics, the presentation of the results is divided into the categories of the different consequences for sampling quality, namely sampling composition, unit nonresponse and item nonresponse. Each of these sections is related to the hypotheses. Before considering the incentive effects on the socio-structural composition of the sample, the results in Table I indicate the impact of incentives on the telephone recruitment effort. While using the brochure 30.9 per cent were recruited to receive the survey documents, the recruitment rates for the $€ 2$ token ( 36.6 per cent), the $€ 5$ token ( 39.7 per cent) and the voucher (39 per cent) were considerably higher. This difference between non-cash and monetary incentives becomes even more pronounced when one compares the overall response rates (see Table 2). The response rate differences between the token incentives and the voucher are less pronounced for the telephone recruitment (approximately 3 per cent; see Table I) and the final sample (approximately 2 per cent; see Table 2 ).

However, the response rate alone is an insufficient quality criterion for a sample (see Groves 2006) but considering the composition of the sample instead is decisive. According to Groves, potential bias due to sampling problems can affect each variable, although the distinction between error terms and relevant variance for the variables of interest is difficult to identify. Therefore, sample quality can often only be assessed according to the distribution of sociodemographic variables when high-quality reference data is available. Since recruit-

Table 2: Comparison of distributions within the incentive group samples

\begin{tabular}{lccccc}
\hline \multicolumn{1}{c}{ Variables } & Brochure & $€ 2$ token & $€ 5$ token & Voucher & Total \\
\hline Education & & & & & \\
Max. compulsory schooling & $2(1.2 \%)$ & $8(3.1 \%)$ & $13(4.8 \%)$ & $12(4.7 \%)$ & $35(3.7 \%)$ \\
Apprenticeship & $40(23.8 \%)$ & $75(29.5 \%)$ & $74(27.4 \%)$ & $84(32.6 \%)$ & $273(28.7 \%)$ \\
Vocational or commercial school & $24(14.3 \%)$ & $18(7.1 \%)$ & $43(15.9 \%)$ & $22(8.5 \%)$ & $107(11.3 \%)$ \\
Matura & $46(27.4 \%)$ & $69(27.2 \%)$ & $63(23.3 \%)$ & $59(22.9 \%)$ & $237(24.9 \%)$ \\
Higher degree after Matura & $10(6.0 \%)$ & $13(5.1 \%)$ & $12(4.4 \%)$ & $12(4.7 \%)$ & $47(4.9 \%)$ \\
University degree & $46(27.4 \%)$ & $71(28.0 \%)$ & $65(24.1 \%)$ & $69(26.7 \%)$ & $251(26.4 \%)$ \\
Occupational position & & & & & \\
Clerks & $85(44.7 \%)$ & $123(43.6 \%)$ & $133(45.2 \%)$ & $127(44.9 \%)$ & $468(44.6 \%)$ \\
Worker & $5(2.6 \%)$ & $25(8.9 \%)$ & $20(6.8 \%)$ & $20(7.1 \%)$ & $70(6.7 \%)$ \\
Civil servant & $19(10.0 \%)$ & $26(9.2 \%)$ & $22(7.5 \%)$ & $19(6.7 \%)$ & $86(8.2 \%)$ \\
Contract agent & $11(5.8 \%)$ & $13(4.6 \%)$ & $14(4.8 \%)$ & $25(8.8 \%)$ & $63(6.0 \%)$ \\
Pensioner & $32(16.8 \%)$ & $39(13.8 \%)$ & $35(11.9 \%)$ & $32(11.3 \%)$ & $138(13.2 \%)$ \\
Unemployed (inactive) & $24(12.6 \%)$ & $34(12.1 \%)$ & $42(14.3 \%)$ & $40(14.1 \%)$ & $140(13.3 \%)$ \\
Self-employed & $14(7.4 \%)$ & $22(7.8 \%)$ & $28(9.5 \%)$ & $20(7.1 \%)$ & $84(8.0 \%)$ \\
Personal income & & & & & $10 \%$ \\
Up to 1,300€ & $43(24.0 \%)$ & $68(25.3 \%)$ & $65(23.0 \%)$ & $66(24.3 \%)$ & $242(24.1 \%)$ \\
1,301 to 2,500€ & $48(26.8 \%)$ & $93(34.6 \%)$ & $95(33.7 \%)$ & $83(30.5 \%)$ & $320(31.8 \%)$ \\
2,501 to 4,000€ & $52(29.1 \%)$ & $61(22.7 \%)$ & $83(29.4 \%)$ & $71(26.1 \%)$ & $267(26.6 \%)$ \\
More than 4,000€ & $36(20.1 \%)$ & $47(17.5 \%)$ & $39(13.8 \%)$ & $52(19.1 \%)$ & $175(17.4 \%)$ \\
\hline Sample & 190 & 282 & 294 & 283 & 1049 \\
Sampling frame & 1115 & 1046 & 1056 & 1032 & 4249 \\
Response rate & $27.0 \%$ & $27.8 \%$ & $27.4 \%$ & $24.7 \%$ \\
\hline
\end{tabular}


ment from the micro-census sample was highly representative for Austria, the experimental data can be considered representative regarding sociodemographic characteristics. ${ }^{6}$ Consequently, the following discussion focuses on indicators of social inequality that influence the effectiveness of incentives, and reflections on the sample compositions will be limited to those indicators.

\subsection{Sample composition}

Taking into consideration the composition of the samples in relation to education, the results support Hia, as people who hold the compulsory school-leaving certificate or have completed an apprenticeship are better addressees for monetary incentives rather than the brochure (see Table 2). Comparing the two token groups, differences are evident in the category of technical or commercial schools, with higher shares in the $€ 5$ group. The voucher is more attractive for people who have com- pleted an apprenticeship.

In terms of occupational status, the number of civil servants and pensioners represented in the brochure group is higher than in the other three groups, which confirms Hzb. The differences between the groups offered tokens and vouchers are once again small (approximately 2 per cent), except for the contract staff, who appear almost twice as frequently in the voucher group.

There are not great differences in personal income between the four groups for individuals with an income of up to $€ \mathrm{I}, 3 \mathrm{OO}$. Persons in the second income group from $€_{I, 30 I}$ to $€ 2,500$ are more strongly represented in the groups with monetary incentives than in the brochure group. The brochure and voucher groups do not differ significantly between the two higher-income groups. Interestingly, the share of persons with an income of $€ 2,5$ OI to $€ 4$, ooo is the lowest among the $€ 2$ token group. The same applies to persons with an income of more than $€ 4,000$ for the $€ 5$ token group. This could

Table 3: Distribution of response and nonresponse according to incentive group

\begin{tabular}{|c|c|c|c|c|c|c|c|c|}
\hline \multirow[t]{2}{*}{ Variable } & \multicolumn{2}{|c|}{ Brochure } & \multirow{2}{*}{$\begin{array}{c}€ 2 \text { token } \\
\text { nonresponse }\end{array}$} & \multirow[b]{2}{*}{ Response } & \multirow{2}{*}{$\begin{array}{c}€ 5 \text { token } \\
\text { nonresponse }\end{array}$} & \multirow[b]{2}{*}{ Response } & \multirow{2}{*}{$\begin{array}{c}\text { Voucher } \\
\text { nonresponse }\end{array}$} & \multirow[b]{2}{*}{ Response } \\
\hline & Nonresponse & Response & & & & & & \\
\hline \multicolumn{9}{|l|}{ Education } \\
\hline Max. compulsory schooling & $127(98.4 \%)$ & $2(1.6 \%)$ & $132(94.3 \%)$ & $8(5.7 \%)$ & $147(91.9 \%)$ & $13(8.1 \%)$ & $131(91.6 \%)$ & $12(8.4 \%)$ \\
\hline Apprenticeship & $362(90.0 \%)$ & $40(10.0 \%)$ & $314(80.7 \%)$ & $75(19.3 \%)$ & $308(80.6 \%)$ & $74(19.4 \%)$ & $318(79.1 \%)$ & $84(20.9 \%)$ \\
\hline $\begin{array}{l}\text { Vocational or commercial } \\
\text { school }\end{array}$ & $109(82.0 \%)$ & $24(18.0 \%)$ & $92(83.6 \%)$ & $18(16.4 \%)$ & $85(66.4 \%)$ & $43(33.6 \%)$ & $81(79.4 \%)$ & $21(20.6 \%)$ \\
\hline Matura & $146(76.0 \%)$ & $46(24.0 \%)$ & $89(56.3 \%)$ & $69(43.7 \%)$ & 99 (61.1\%) & $63(38.9 \%)$ & $83(58.5 \%)$ & $59(41.5 \%)$ \\
\hline Higher degree after Matura & $18(64.3 \%)$ & $10(35.7 \%)$ & $15(53.6 \%)$ & $13(46.4 \%)$ & $8(40.0 \%)$ & $12(60.0 \%)$ & $18(60.0 \%)$ & $12(40.0 \%)$ \\
\hline University degree & $87(65.4 \%)$ & $46(34.6 \%)$ & $77(52.0 \%)$ & $71(48.0 \%)$ & $67(50.8 \%)$ & $65(49.2 \%)$ & $63(47.7 \%)$ & $69(52.3 \%)$ \\
\hline \multicolumn{9}{|l|}{ Occupational position } \\
\hline Clerks & $293(77.5 \%)$ & $85(22.5 \%)$ & $233(65.4 \%)$ & $123(34.6 \%)$ & $229(63.3 \%)$ & $133(36.7 \%)$ & $211(62.4 \%)$ & $127(37.6 \%)$ \\
\hline Worker & $145(96.7 \%)$ & $5(3.3 \%)$ & $137(84.6 \%)$ & $25(15.4 \%)$ & $128(86.5 \%)$ & $20(13.5 \%)$ & $128(86.5 \%)$ & $20(13.5 \%)$ \\
\hline Civil servant & $33(63.5 \%)$ & 19 (36.5\%) & $27(50.9 \%)$ & $26(49.1 \%)$ & $20(47.6 \%)$ & $22(52.4 \%)$ & $21(52.5 \%)$ & 19 (47.5\%) \\
\hline Contract agent & $40(78.4 \%)$ & $11(21.6 \%)$ & $30(69.8 \%)$ & $13(30.2 \%)$ & $13(48.1 \%)$ & $14(51.9 \%)$ & $25(50.0 \%)$ & $25(50.0 \%)$ \\
\hline Pensioner & $185(85.3 \%)$ & $32(14.7 \%)$ & $175(81.8 \%)$ & $39(18.2 \%)$ & $199(85.0 \%)$ & 35 (15.0\%) & $185(85.3 \%)$ & $32(14.7 \%)$ \\
\hline Unemployed (inactive) & $140(85.4 \%)$ & $24(14.6 \%)$ & $107(75.9 \%)$ & $34(24.1 \%)$ & $120(74.1 \%)$ & $42(25.9 \%)$ & $119(74.8 \%)$ & $40(25.2 \%)$ \\
\hline Self-employed & $83(85.6 \%)$ & $14(14.4 \%)$ & $71(76.3 \%)$ & $22(23.7 \%)$ & $59(67.8 \%)$ & 28 (32.2\%) & 68 (77.3\%) & $20(22.7 \%)$ \\
\hline
\end{tabular}

6 Due to the micro-census' sampling design as a household survey with oversampling in smaller federal states, the data necessitates the application of design weights to make it as representative as possible. Statistics Austria calculated the design weights for the sample data with an iterative proportional fitting procedure based on administrative data (see Meraner et al. 20I6). A potential source of bias is the survey history of the respondents in the micro-census, including survey fatigue or experiences with survey modalities, which could affect the results (see Gumprecht 20IO). support our argument that higher income groups do not distinguish between monetary and non-monetary incentives ( $\mathrm{H} 2 \mathrm{a})$.

Concerning the distributions within the incentive groups, non-cash incentives seem to be less attractive to lower-income groups (supporting $\mathrm{H} 2 \mathrm{~b}$ ), workers (supporting $\mathrm{H}$ 3a) and peoplewith lower education levels (sup- 
porting Hib), when compared to the monetary incentive groups. Across the monetary incentive groups there are only minor differences in the sample composition.

Since the compositions of the sampling frames differ across incentive groups (see Seymer 2017), nonresponse should be considered to draw conclusions. The results in Table 3 indicate that for all groups people with the maximum compulsory schooling have the lowest response rates (maximum 8.4 per cent). There is a significantly better but still low response rate evident among people who have completed an apprenticeship or who have a vocational or commercial school certificate (IO-2O per cent). It is only in the $€ 5$ group that 33.6 per cent of the total number of people with technical or commercial schooling were successfully recruited. For people with a Matura degree or higher, the response rates are significantly higher than the overall response rate of 26 per cent (see Table 2). Within the groups with monetary incentives, at least 38.9 per cent, and at most 52.3 per cent, were recruited. ${ }^{7}$ Only the brochure group had significantly lower response rates within the three highest education levels, with a maximum of 35.7 per cent. These results clearly support our hypotheses on education (Hia and $\mathrm{Hib}$ ).

When one looks at the response rates of the different occupations, a low response rate within the brochure group, which only reaches for civil servants above the 24.7 per cent overall response rate, is once again evident. In groups with monetary incentives, there are difficulties in recruiting workers (confirming H3a), retirees (contradicting $\mathrm{H}_{3} \mathrm{~b}$ ), the unemployed and the self-employed. All other professions could be recruited to at least the level of 30 per cent, and sometimes more than 50 per cent.

\subsection{Unit nonresponse}

At this point, it can already be stated that monetary incentives achieve a significantly higher response rate and are met with better acceptance than incentives in kind. The results for the groups with monetary incentives are much more homogeneous and only isolated differences are present, such as the higher response rate for medium-level qualifications in the $€ 5$ group.

The results are confirmed in a multivariate logistic regression model for factors influencing unit nonresponse (see Table 4). The test statistics and the number of effects across the different models in Table 4 show that education and occupation are the main predictors of survey participation, and the results indicate differences between the models for incentives in kind and monetary incentives. ${ }^{8}$ Educational and professional predictors are

7 The 60 per cent figure in the $€ 5$ group is not meaningful due to the small $\mathrm{n}$ of 20 .

8 The results are robust against recoding education or occupation into larger groups (Seymer 20I7). most noticeable in all models and confirm $\mathrm{HI}$ and $\mathrm{H} 3$. Meanwhile the income effect can be exclusively proven for the brochure group when one limits the evidence for $\mathrm{H} 2$. The model for the brochure group indicates that incentives in kind have a worse performance for people with lower education levels, workers and those on low incomes. The models for monetary incentives display greater similarities, although differences do exist. A similar educational effect can be observed for all three models, while there are slight differences in the middleand higher-education attainment levels. The voucher addressed people with university degrees best, while in the two token groups those with alternative higher degrees showed comparable response rates to people with university degrees. These results demonstrated the opposite to our assumption in Hib (see Figure I).

The three monetary incentive groups differ more explicitly in their professional position. In the $€ 2$ group, only self-employed workers are harder to recruit, while in the $€ 5$ group, workers and pensioners are less likely to respond than all other occupational groups. In the case of vouchers, there is a lower chance of recruiting workers, the unemployed and the self-employed. The lower chance of recruiting workers is consistently confirmed in three out of four experimental groups, which provides robust evidence for H3a. Meanwhile, two out of three monetary incentive groups exhibit higher response rates among the self-employed. Figure 2 support the findings from the multivariate analysis in the bivariate descriptive bar chart.

Interestingly, the results indicate differences in origin but not in citizenship. These figures result from the higher response rates of people from EUI5 foreign countries when compared to Austrians and non-EUi5 foreigners 9 . However, when comparing Austrians to nonAustrians, the higher response rates of EUI5 foreigners compensates for the lower response rates of non-EUi5 foreigners. Consequently, non-EUI5 foreigners are more difficult to recruit and respond less to monetary incentives. It is particularly interesting that this origin effect occurs only in the three monetary incentive groups. This would suggest that monetary incentives target EUI5 citizens particularly well, while non-EUI5 foreigners are less appropriate addressees for these incentives.

To sum up the results from the unit nonresponse analysis, the positive effect of incentives on people with lower education levels, which has been identified in other studies (Petrolia/Bhattacharjee 2009), cannot be confirmed. Instead, the results indicate that the effects of incentives are quite similar from medium education levels up and that significantly more people with a me-

9 Germans are the second largest population subgroup without Austrian citizenship in Austria. Germans encounter no language barrier in the country and enjoy almost identical rights as Austrians. Furthermore, migrants from Germany are often well educated 
Table 4: Odds ratios of logistic regression on unit response by incentive group

\begin{tabular}{|c|c|c|c|c|c|}
\hline & & \multicolumn{4}{|c|}{ Response Rate } \\
\hline & & $\begin{array}{l}\text { Brochure } \\
\text { logistic }\end{array}$ & $\begin{array}{l}€ 2 \text { Token } \\
\text { logistic }\end{array}$ & $\begin{array}{l}\text { €5 Token } \\
\text { logistic }\end{array}$ & $\begin{array}{l}\text { Voucher } \\
\text { logistic }\end{array}$ \\
\hline & Constant & $\begin{array}{l}0.127 \\
t=-3.729 * * *\end{array}$ & $\begin{aligned} & 0.212 \\
t= & -2.985^{* \star *}\end{aligned}$ & $\begin{array}{c}0.539 \\
t=-1.253\end{array}$ & $\begin{array}{c}0.549 \\
t=-1.235\end{array}$ \\
\hline \multirow[t]{2}{*}{$\begin{array}{l}\text { Age } \\
\text { (Ref }=25 \text { to } 64 \text { years })\end{array}$} & 65 years and older & $\begin{array}{c}0.696 \\
t=-0.903\end{array}$ & $\begin{array}{c}0.857 \\
t=-0.413\end{array}$ & $\begin{array}{c}1.052 \\
t=0.137\end{array}$ & $\begin{aligned} & 0.470 \\
t= & -2.045^{* * *}\end{aligned}$ \\
\hline & Up to 24 years & $\begin{array}{c}1.037 \\
t=0.094\end{array}$ & $\begin{array}{c}0.787 \\
t=-0.632\end{array}$ & $\begin{array}{c}0.948 \\
t=-0.168\end{array}$ & $\begin{array}{c}1.583 \\
t=1.288\end{array}$ \\
\hline $\begin{array}{l}\text { In partnership } \\
(\text { Ref }=\text { No) }\end{array}$ & Yes & $\begin{array}{c}1.417 \\
t=1.689^{*}\end{array}$ & $\begin{array}{c}1.166 \\
t=0.835\end{array}$ & $\begin{array}{c}1.503 \\
t=2.277^{\star *}\end{array}$ & $\begin{aligned} & 0.127 \\
t= & 2.468^{\star *}\end{aligned}$ \\
\hline $\begin{array}{l}\text { Household size } \\
(\text { Ref }=\text { Household }(5+))\end{array}$ & Household (1-4 Persons) & $\begin{array}{c}1.213 \\
t=0.957\end{array}$ & $\begin{array}{c}1.172 \\
t=0.865\end{array}$ & $\begin{array}{c}0.858 \\
t=-0.863\end{array}$ & $\begin{array}{c}0.947 \\
t=-0.300\end{array}$ \\
\hline \multirow[t]{5}{*}{$\begin{array}{l}\text { Education } \\
\text { (Ref = University degree) }\end{array}$} & Higher degree after Matura & $\begin{array}{c}0.924 \\
t=-0.172\end{array}$ & $\begin{array}{c}0.923 \\
t=-0.186\end{array}$ & $\begin{array}{c}1.209 \\
t=0.368\end{array}$ & $\begin{aligned} & 0.425 \\
t= & -1.970 * *\end{aligned}$ \\
\hline & $\begin{array}{l}\text { Vocational or commercial } \\
\text { school }\end{array}$ & $\begin{aligned} & 0.440 \\
t= & -2.656^{\star * *}\end{aligned}$ & $\begin{array}{c}0.221 \\
t=-4.557^{\star * \star}\end{array}$ & $\begin{array}{c}0.604 \\
t=-1.837^{*}\end{array}$ & $\begin{aligned} & 0.263 \\
t= & -4.146^{\star * *}\end{aligned}$ \\
\hline & Apprenticeship & $\begin{aligned} & 0.254 \\
t= & -4.962^{* * *}\end{aligned}$ & $\begin{array}{c}0.302 \\
t=-5.090^{\star \star *}\end{array}$ & $\begin{aligned} & 0.304 \\
t= & -4.982^{* * *}\end{aligned}$ & $\begin{aligned} & 0.258 \\
t= & -5.503^{* * *}\end{aligned}$ \\
\hline & Matura & $\begin{array}{c}0.637 \\
t=-1.670^{*}\end{array}$ & $\begin{array}{c}0.916 \\
t=-0.357\end{array}$ & $\begin{array}{c}0.651 \\
t=-1.684^{*}\end{array}$ & $\begin{array}{c}0.618 \\
t=-1.807^{*}\end{array}$ \\
\hline & Max. compulsory schooling & $\begin{aligned} & 0.043 \\
t= & -4.162^{* * *}\end{aligned}$ & $\begin{aligned} & 0.105 \\
t= & -5.322^{\star * *}\end{aligned}$ & $\begin{array}{c}0.130 \\
\mathrm{t}= \\
-5.682^{* * *}\end{array}$ & $\begin{array}{c}0.115 \\
t=-5.684^{* * *}\end{array}$ \\
\hline \multirow[t]{6}{*}{$\begin{array}{l}\text { Professional position } \\
\text { (Ref = Clerk) }\end{array}$} & Worker & $\begin{aligned} & 0.299 \\
t= & -2.445^{\star *}\end{aligned}$ & $\begin{array}{c}0.727 \\
t=-1.113\end{array}$ & $\begin{array}{c}0.457 \\
t=-2.698^{* * *}\end{array}$ & 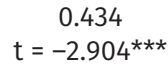 \\
\hline & Civil servant & $\begin{array}{c}1.275 \\
t=0.696\end{array}$ & $\begin{array}{c}1.295 \\
t=0.786\end{array}$ & $\begin{array}{c}1.641 \\
t=1.319\end{array}$ & $\begin{array}{c}1.048 \\
t=0.124\end{array}$ \\
\hline & Pensioner & $\begin{array}{c}1.063 \\
t=0.160\end{array}$ & $\begin{array}{c}0.568 \\
t=-1.556\end{array}$ & $\begin{array}{c}0.349 \\
t=-2.895^{\star * *}\end{array}$ & $\begin{array}{c}0.639 \\
t=-1.401\end{array}$ \\
\hline & Non-working (inactive) & $\begin{array}{c}0.946 \\
t=-0.186\end{array}$ & $\begin{array}{c}0.749 \\
t=-1.082\end{array}$ & $\begin{array}{c}0.792 \\
t=-0.991\end{array}$ & $\begin{aligned} & 0.582 \\
t= & -2.084^{* *}\end{aligned}$ \\
\hline & Self-employed & $\begin{array}{c}0.543 \\
t=-1.644\end{array}$ & $\begin{aligned} & 0.520 \\
t= & -2.053^{* *}\end{aligned}$ & $\begin{array}{c}0.735 \\
t=-1.045\end{array}$ & $\begin{aligned} & 0.442 \\
t= & -2.529^{* *}\end{aligned}$ \\
\hline & Contract agents & $\begin{array}{c}0.747 \\
t=-0.703\end{array}$ & $\begin{array}{c}0.629 \\
t=-1.198\end{array}$ & $\begin{array}{c}1.487 \\
t=0.900\end{array}$ & $\begin{array}{c}1.070 \\
t=0.189\end{array}$ \\
\hline $\begin{array}{l}\text { Austrian Citizenship } \\
\text { (Ref = Yes) }\end{array}$ & No & $\begin{array}{c}0.985 \\
t=-0.041\end{array}$ & $\begin{array}{c}1.286 \\
t=0.689\end{array}$ & $\begin{array}{c}0.925 \\
t=-0.222\end{array}$ & $\begin{array}{c}0.759 \\
t=-0.717\end{array}$ \\
\hline $\begin{array}{l}\text { Origin } \\
(\text { Ref = non-EU15) }\end{array}$ & EU15 with Austria & $\begin{array}{c}1.980 \\
t=1.542\end{array}$ & $\begin{aligned} & 3.283 \\
\mathrm{t}= & 2.843^{\star * *}\end{aligned}$ & $\begin{array}{c}2.127 \\
t=1.894^{*}\end{array}$ & $\begin{array}{c}2.791 \\
t=2.548^{\star *}\end{array}$ \\
\hline \multirow[t]{5}{*}{ Income } & Quintile (5=highest) & $\begin{aligned} & 1.187 \\
t & =2.253^{* *}\end{aligned}$ & $\begin{array}{c}1.091 \\
t=1.409\end{array}$ & $\begin{array}{c}0.986 \\
t=-0.242\end{array}$ & $\begin{array}{c}0.960 \\
t=-0.640\end{array}$ \\
\hline & McFadden Pseudo- $\mathrm{R}^{2}$ & 0.131 & 0.130 & 0.127 & 0.127 \\
\hline & Observations & 1,001 & 956 & 975 & 937 \\
\hline & Log Likelihood & -393.587 & -475.859 & -502.417 & -480.354 \\
\hline & Akaike Inf. Crit. & 825.175 & 989.719 & $1,042.834$ & 998.707 \\
\hline
\end{tabular}

Note: ${ }^{*} \mathrm{p}<0.1 ;{ }^{* *} \mathrm{p}<0.05 ;{ }^{* *} \mathrm{p}<0.01$; gender was tested but yield no significant results in any model an was dropped in favour of a parsimonous model. 
Figure 1: Response rates by education categories and incentive groups

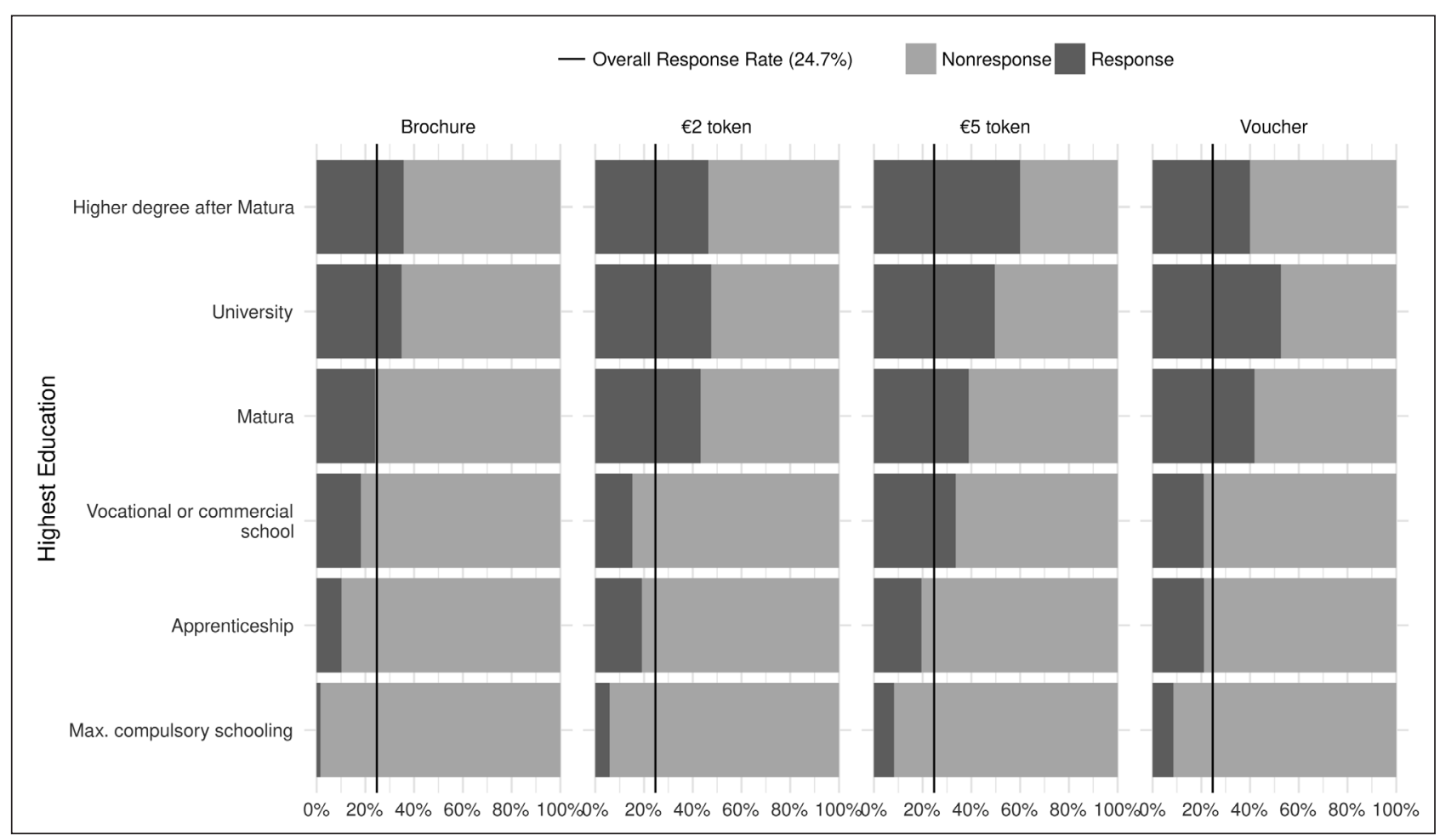

Figure 2: Response rates by occupation categories and incentive groups

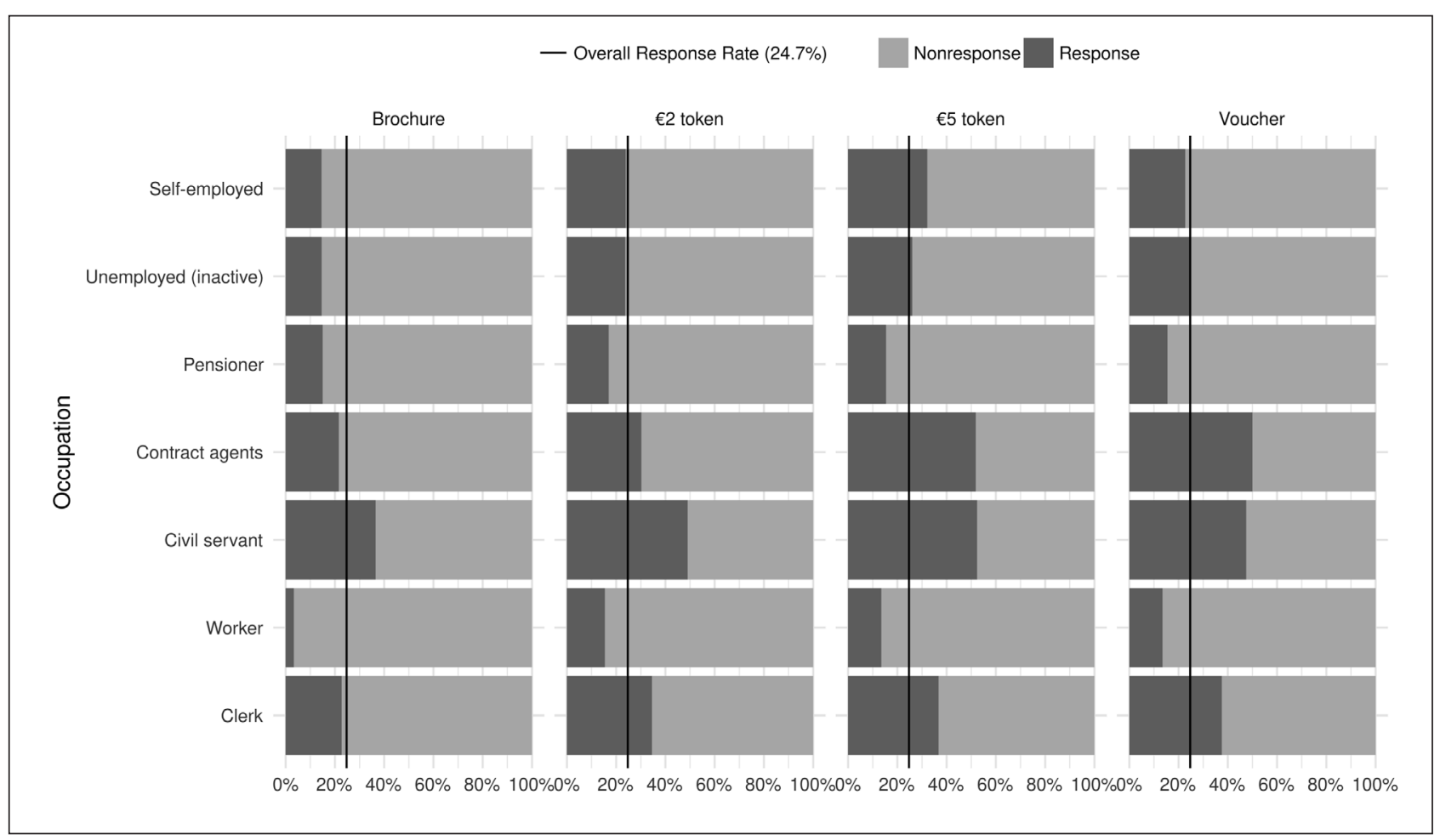


Table 5: Poisson regression on the item nonresponse by incentive group

\begin{tabular}{|c|c|c|c|c|c|}
\hline & \multirow[b]{3}{*}{ Constant } & \multicolumn{4}{|c|}{ Count of Item Nonresponse } \\
\hline & & $\begin{array}{l}\text { Brochure } \\
\text { Poisson }\end{array}$ & $\begin{array}{l}€ 2 \text { Token } \\
\text { Poisson }\end{array}$ & $\begin{array}{l}€ 5 \text { Token } \\
\text { Poisson }\end{array}$ & $\begin{array}{l}\text { Voucher } \\
\text { Poisson }\end{array}$ \\
\hline & & $\begin{array}{l}1.705 \\
t=0.801\end{array}$ & $\begin{array}{c}1.353 \\
t=0.745\end{array}$ & $\begin{aligned} & 4.327 \\
\mathrm{t}= & 4.981^{\star * *}\end{aligned}$ & $\begin{aligned} & 3.788 \\
t= & 5.186^{\star * *}\end{aligned}$ \\
\hline \multirow[t]{2}{*}{$\begin{array}{l}\text { Age } \\
\text { (Ref = } 25 \text { to } 64 \text { years) }\end{array}$} & 65 years and older & $\begin{array}{c}0.833 \\
t=-0.666\end{array}$ & $\begin{array}{c}0.903 \\
t=-0.542\end{array}$ & $\begin{aligned} & 1.741 \\
t= & 2.390^{\star *}\end{aligned}$ & $\begin{array}{c}0.830 \\
t=-0.774\end{array}$ \\
\hline & Up to 24 years & $\begin{array}{c}1.719 \\
\mathrm{t}=2.471^{\star *}\end{array}$ & $\begin{aligned} & 0.393 \\
t= & -3.330 * \star *\end{aligned}$ & $\begin{array}{c}1.140 \\
t=0.776\end{array}$ & $\begin{aligned} & 1.772 \\
t= & 3.606^{* * *}\end{aligned}$ \\
\hline $\begin{array}{l}\text { In partnership } \\
\text { (Ref = No) }\end{array}$ & Yes & $\begin{array}{c}1.035 \\
t=0.285\end{array}$ & $\begin{array}{c}0.752 \\
t=-3.045^{\star * *}\end{array}$ & $\begin{array}{c}1.171 \\
t=1.586\end{array}$ & $\begin{array}{c}0.886 \\
t=-1.293\end{array}$ \\
\hline $\begin{array}{l}\text { Household size } \\
(\text { Ref }=\text { Household }(5+))\end{array}$ & Household (1-4 Persons) & $\begin{array}{c}1.131 \\
t=1.128\end{array}$ & $\begin{array}{c}0.753 \\
\mathrm{t}= \\
-3.020^{\star * *}\end{array}$ & $\begin{array}{c}0.861 \\
t=-1.503\end{array}$ & $\begin{aligned} & 0.829 \\
t= & -2.018^{* *}\end{aligned}$ \\
\hline \multirow[t]{5}{*}{$\begin{array}{l}\text { Education } \\
\text { (Ref = University degree) }\end{array}$} & Higher degree after Matura & $\begin{array}{c}1.485 \\
t=0.702\end{array}$ & $\begin{array}{c}2.075 \\
t=2.327^{* *}\end{array}$ & $\begin{array}{c}1.067 \\
t=0.290\end{array}$ & $\begin{array}{c}0.984 \\
t=-0.089\end{array}$ \\
\hline & $\begin{array}{l}\text { Vocational or commercial } \\
\text { school }\end{array}$ & $\begin{array}{c}1.510 \\
t=0.723\end{array}$ & $\begin{array}{c}1.644 \\
t=1.431\end{array}$ & $\begin{array}{c}0.819 \\
t=-0.842\end{array}$ & $\begin{array}{c}0.740 \\
t=-1.264\end{array}$ \\
\hline & Apprenticeship & $\begin{array}{c}1.292 \\
t=0.446\end{array}$ & $\begin{array}{c}1.471 \\
t=1.208\end{array}$ & $\begin{array}{c}1.061 \\
t=0.265\end{array}$ & $\begin{array}{c}0.820 \\
t=-1.083\end{array}$ \\
\hline & Matura & $\begin{array}{c}1.558 \\
t=0.785\end{array}$ & $\begin{array}{c}1.554 \\
t=1.368\end{array}$ & $\begin{array}{c}0.832 \\
t=-0.796\end{array}$ & $\begin{array}{c}1.007 \\
t=0.037\end{array}$ \\
\hline & Max. compulsory schooling & $\begin{array}{c}1.290 \\
t=0.426\end{array}$ & $\begin{array}{c}2.274 \\
\mathrm{t}=2.392^{\star *}\end{array}$ & $\begin{array}{c}2.065 \\
\mathrm{t}=2.777^{\star \star *}\end{array}$ & $\begin{aligned} & 0.474 \\
t= & -2.483^{* *}\end{aligned}$ \\
\hline \multirow[t]{6}{*}{$\begin{array}{l}\text { Professional position } \\
\text { (Ref = Clerk) }\end{array}$} & Worker & $\begin{array}{c}1.427 \\
t=1.392\end{array}$ & $\begin{array}{c}0.764 \\
t=-1.535\end{array}$ & $\begin{array}{c}0.694 \\
t=-1.927^{*}\end{array}$ & $\begin{array}{c}1.035 \\
t=0.211\end{array}$ \\
\hline & Civil servant & $\begin{aligned} & 0.654 \\
t= & -1.974 * *\end{aligned}$ & $\begin{aligned} & 0.701 \\
t= & -2.072^{\star *}\end{aligned}$ & $\begin{array}{c}0.372 \\
t=-4.296 * * *\end{array}$ & $\begin{array}{c}1.898 \\
t=4.558^{* * *}\end{array}$ \\
\hline & Pensioner & $\begin{array}{c}1.454 \\
t=1.936^{* *}\end{array}$ & $\begin{array}{c}0.668 \\
t=-1.680^{*}\end{array}$ & $\begin{array}{c}1.017 \\
t=0.092\end{array}$ & $\begin{array}{c}0.785 \\
t=-1.346\end{array}$ \\
\hline & Unemployed (inactive) & $\begin{array}{c}1.043 \\
t=0.163\end{array}$ & $\begin{array}{c}1.553 \\
\mathrm{t}=2.342^{\star *}\end{array}$ & $\begin{array}{c}0.484 \\
t=-3.004^{* * *}\end{array}$ & $\begin{array}{c}1.364 \\
t=1.594\end{array}$ \\
\hline & Self-employed & $\begin{array}{c}0.781 \\
t=-1.439\end{array}$ & $\begin{array}{c}1.280 \\
t=1.890^{*}\end{array}$ & $\begin{array}{c}1.267 \\
\mathrm{t}=2.079^{\star *}\end{array}$ & $\begin{array}{c}0.968 \\
t=-0.250\end{array}$ \\
\hline & Contract agents & $\begin{array}{c}1.284 \\
t=1.295\end{array}$ & $\begin{array}{c}1.342 \\
t=1.960^{*}\end{array}$ & $\begin{aligned} & 0.695 \\
t= & -2.033^{* *}\end{aligned}$ & $\begin{aligned} & 1.482 \\
t= & 2.616^{\star * *}\end{aligned}$ \\
\hline $\begin{array}{l}\text { Austrian Citizenship } \\
\text { (Ref = Yes) }\end{array}$ & No & $\begin{array}{c}0.931 \\
t=-0.303\end{array}$ & $\begin{array}{c}1.601 \\
t=3.112^{\star \star \star}\end{array}$ & $\begin{array}{c}0.799 \\
t=-1.134\end{array}$ & $\begin{array}{c}0.882 \\
t=-0.622\end{array}$ \\
\hline $\begin{array}{l}\text { Origin } \\
(\text { Ref = non-EU15) }\end{array}$ & EU15 with Austria & $\begin{array}{c}1.459 \\
t=1.235\end{array}$ & $\begin{array}{c}1.377 \\
t=1.282\end{array}$ & $\begin{array}{c}0.571 \\
t=-2.747^{\star \star *}\end{array}$ & $\begin{array}{c}0.744 \\
t=-1.560\end{array}$ \\
\hline \multirow[t]{5}{*}{ Income } & Quintile (5=highest) & $\begin{array}{c}0.900 \\
t=-2.578^{\star \star \star}\end{array}$ & $\begin{array}{c}1.017 \\
t=0.524\end{array}$ & $\begin{array}{c}0.975 \\
t=-0.807\end{array}$ & $\begin{array}{c}1.012 \\
t=0.369\end{array}$ \\
\hline & Pseudo- $\mathrm{R}^{2}$ & 0.074 & 0.114 & 0.111 & 0.087 \\
\hline & Observations & 167 & 254 & 268 & 254 \\
\hline & Log Likelihood & -412.390 & -614.888 & -625.364 & -620.718 \\
\hline & Akaike Inf. Crit. & 862.780 & $1,267.776$ & $1,288.729$ & $1,279.436$ \\
\hline
\end{tabular}

Note: ${ }^{*} \mathrm{p}<0.1 ;{ }^{* *} \mathrm{p}<0.05 ;{ }^{* * *} \mathrm{p}<0.01$ 
dium or higher education level are motivated by monetary incentives in comparison to those with lower education levels.

\subsection{Item nonresponse}

Beyond the unit nonresponse, the item nonresponse is a central quality characteristic for sampling. In Table 5, the item nonresponse is related to the social inequality characteristics based on a Poisson regression on the number of item nonresponses with the same predictors as in Table 4. All questionnaires with a maximum of 15 missing answers were considered. Questionnaires with more than 15 responses are classified as unit nonresponse.

The results from the table illustrate that education is of secondary importance for the item nonresponse. The most important predictors are age, professional position and citizenship. Interestingly, the results for the item nonresponse are inconsistent with those for the unit nonresponse. The youngest age group shows the lowest item nonresponse in the $€ 2$ token group and the highest in the voucher and brochure group, while the $€ 5$ token group exhibits no age effect. As these heterogeneous results are consistent across the other predictors, it seems plausible to consider these differences to be unrelated to the incentives. A pooled Poisson regression model, with incentives as the only predictors, lacks any significant differences between the incentive groups. Accordingly, the differences identified in Table 5 need to be interpreted as selective differences in the sample composition rather than as incentive effects.

\section{Summary and Discussion}

Based on the theory of social exchange, this article has addressed the association between indicators of social inequality and the impact of incentives. Several hypotheses were derived for this purpose, which were partially confirmed by analysing the composition of the samples, unit nonresponse and item nonresponse. The expected education effect is confirmed in the results supporting Hia and Hrb. The non-monetary incentive performs best for those with high education levels and worst amongst those with low education levels (Hia). The sample composition and the results from the logistic regression on unit response validate $\mathrm{HI}$, with the lowest response rates among people with maximum compulsory schooling. The education effects differ across non-monetary and monetary incentives, while amongst the monetary incentive groups the effects are homogenous. The results yield partial evidence for an income effect as hypothesised in $\mathrm{H} 2$, since the non-monetary incentive group indicated higher response rates for higher-income groups. $\mathrm{H} 3 \mathrm{a}$ is supported by the analysis of unit nonresponse and the composition of the sample that confirms that workers are more difficult to recruit. Monetary incentives perform better than non-monetary incentives, and the $€ 2$ group is the only group without significantly lower unit response among workers.

Taking the pensioners $\left(\mathrm{H}_{3} b\right)$ into consideration, a comparison of incentive groups reveals no distinct variations. When one compares the distribution within incentive groups, pensioners are represented slightly more in the brochure group, but the nonresponse rate is only higher for the $€ 2$ token group. The logistic regression on unit response indicates lower response rates for the $€ 5$ group. Meanwhile, pensioners receiving the brochure tend to exhibit higher item nonresponse, and pensioners in the $€ 2$ group demonstrate lower item nonresponse when compared to the $€ 5$ and voucher groups. These outcomes make the comparison of non-monetary and monetary, and voucher and token incentives for pensioners inconclusive. The only supportable conclusion is that response rates for pensioners are independent from the value of the token.

When one compares monetary and non-monetary, token and voucher, and $€ 2$ and $€ 5$ token incentives, the brochure group exhibits the lowest overall response rate and the highest variances across the subgroups. Consequently, the monetary incentives outperform the brochure. Comparing the two token groups against the voucher group yields similar results, as the two cash token groups show only modest and selective differences in sample composition and response rates. The general conclusion to be made is that monetary incentives have a positive effect, with little differences in the incentives' real monetary value. This outcome supports the theoretical claims of social exchange theory about the primacy of symbolic incentives for recruitment. Meanwhile, the difference between monetary and non-monetary incentives manifests the relevance of the usefulness of the symbolic item, which according to Dillman et al. (2014) should increase the benefit of survey participation.

In the wider context of research on survey design, the results need to be considered within their respective limitations. Recruitment from a highly representative micro-census survey provides advantages in terms of the ability to contact respondents and additional information on non-respondents. Simultaneously, the sampling design is predefined by the micro-census's sampling, in which small federal states and larger households are oversampled. As Seymer (2017) points out, these sampling strategies leads to a bias in the sampling frame, which needs to be corrected by design weights. Especially people with non-EU citizenship and lower educated people had lower chances to be recruited.

Conducting a web survey differs systematically from alternative survey methods, such as CATI or face-to- 
face. The literature on nonresponse indicates that there is a common positive effect for prepaid incentives across all survey methods. The results from this study should be considered primarily within the context of web surveys. Furthermore, previous survey participation in the micro-census, recruitment by telephone and the combination of an email and postal reminder will influence the response rate; these effects are controlled for in the comparison of the experimental groups, but they reduce the generalisability of the results.

Alternative factors here are survey mode, sponsorship, the number of contacts, the reminder or the device used to participate in the survey, all of which could be explored to better understand survey participation as a holistic concept. Edwards et al. (2OI4) have shown that survey sponsorship increases survey participation. Converse et al. (2008) have provided evidence for differences in response rates according to the order of the survey modes in mixed-mode surveys. In a meta-analysis, Shih and Fan (2009) provided support for the positive influence of reminder effects on response rates. Meta-analyses are commonly conducted to relate the different survey design factors that influence participation rates to one another (see, for example, Shih/Fan 2009; De Leeuw et al. 2007; Church 1993). Significantly fewer studies have incorporated different survey design aspects into the experimental design as Messer and Dillman have done (2OII). With the steadily growing number of studies on incentives and alternative survey design factors, the implementation of a combination of multiple survey design factors seems to present the most interesting directions for future research to overcome the limitations of meta-analyses.

Despite such limitations, some general lessons can be learned from the experiment in relation to sample composition and survey nonresponse. Incentives certainly increase response rates, but the effect differs significantly across groups that are characterised according to their socio-structural position. Consequently, the sample composition may be distorted, counterbalancing the positive effects of incentives. One possible solution is the application of differential incentives, but these have been criticized for ethical and methodological reasons (see Stähli/Joye 2016, 429). Statistics Austria corrected the potential bias through design weights based on administrative data, which seem to be, methodologically speaking, the most comprehensive approach. Nonetheless, the assumption of equal variance across the unadjusted variables is a strong one. In the general context of increasing survey participation and survey quality, the two holistic approaches by Dillman et al. (20I4) and Groves et al. (2009; 2000) are the best choices for incorporating the incentives when supplemented by additional measures.
The results have implications for the application of web survey data in general. Many public and political debates rely on or demand the inclusion of survey data to be used as fact, and web surveys are often perceived as cost- and time-effective means of gathering it. This article indicates that web surveys suffer from a sampling bias towards people with lower education levels, which is difficult to compensate through incentives. Survey research has steadily increased the quality of surveys, and more importantly shed light on their limitations during the last 50 years. Web surveys, as a rather young survey form, still need to find their place between alternative survey modes, but they are most certainly not the catch-all solution to the challenges of survey research but are only a part of the solution. Offering web surveys as one mode amongst others, when used in combination with incentives, seems to be a promising approach to improve data quality. Nonetheless, our results clearly indicate that web surveys need to engage deep expertise in survey research throughout the sampling process to guarantee that high-quality data is gathered.

\section{Bibliography}

Bethlehem, Jelke/Bart Bakker (2014), The Impact of Nonresponse on Survey Quality, in: Statistical Journal of the IAOS, Vol. 3O(3), 243-248.

Bethlehem, Jelke/Fannie Cobben/Barry Schouten (20II), Handbook of Nonresponse in Household Surveys, New Jersey: Wiley.

Blohm, Michael/Achim Koch (2013), Respondent Incentives in a National Face-to-Face Survey: Effects on Outcome Rates, Sample Composition and Fieldwork Efforts, in: Methoden, Daten, Analysen, Vol. 7(I), 89-I22.

Bourdieu, Pierre (1986), The Forms of Capital, in: Richardson, John G. (ed.), Handbook of Theory and Research for the Sociology of Education. Connecticut: Greenwood Publishing Group, 24I-258.

Bourdieu, Pierre (1979), Public Opinion does not exist, in: Mattelart, Armand/Seth. Siegelaub (ed.), Communication and Class Struggle, New York/Bagnolet: IG/ IMMRC, I24-I3O.

Bünning, Mareike (2016), Soziale Lagen und soziale Schichtung, in: Statistisches Bundesamt (Destatis)/ Wissenschaftszentrum Berlin für Sozialforschung (in Zusammenarbeit mit dem Sozio-ökonomischen Panel (SOEP) am Deutschen Institut für Wirtschaftsforschung) (ed.), Datenreport 2016, Bonn: Bundeszentrale für politische Bildung, 2OI-208.

Church, Allan H. (1993), Estimating the Effect of Incentives on Mail Survey Response Rates: A meta-analysis, in: Public Opinion Quarterly, Vol. 57(I), 62-79.

Converse, Patrick D./Edward W. Wolfe/Xiaoting Huang/ Frederick L. Oswald (2008), Response Rates for 
Mixed-Mode Surveys Using Mail and E-mail/Web, in: American Journal of Evaluation, Vol. 29(I), 99-IO7.

Couper, Mick P./Arie Kapteyn/Matthias Schonlau/Joachim Winter (2007), Noncoverage and nonresponse in an Internet survey, in: Social Science Research, Vol. 36(I), I3I-I48.

Dillman, Don A./Jolene Smyth/Leah Christian (2014), Internet, Phone, Mail, and Mixed-Mode Surveys: The Tailored Design Method, New Jersey: Wiley.

Edwards, Michelle L./Don A. Dillman/Jolene D. Smyth (20I4), An Experimental Test of the Effects of Survey Sponsorship on Internet and Mail Survey Response, in: Public Opinion Quarterly, Vol. 78(3), 734-750.

Erikson, Robert/John H. Goldthorpe/Lucienne Portocarero (2010), Intergenerational Class Mobility and the Convergence Thesis: England, France and Sweden, in: The British Journal of Sociology, Vol. 6I(I), I85-219.

Ernst Stähli, Michèle/Dominique Joye (2016), Incentives as a Possible Measure to Increase Response Rates, in: Wolf, Christof/ Dominique Joye/Tom W. Smith/Yangchi $F u$, (ed.), The SAGE Handbook of Survey Methodology, London: SAGE, 425-440.

Felderer, Barbara/Gerrit Müller/Frauke Kreuter/Joachim Winter (2017), The Effect of Differential Incentives on Attrition Bias: Evidence from the PASS Wave 3 Incentive Experiment, in: Field Methods, Vol. 30(I), 56-69.

Geißler, Rainer (2014), Die Sozialstruktur Deutschlands, Wiesbaden: Springer Fachmedien.

Göritz, Anja S. (2006), Incentives in Web Studies: Methodological Issues and a Review, in: International Journal of Internet Science, Vol. I(I), 58-70.

Grauenhorst, Thomas/Michael Blohm/Achim Koch (2015), Respondent Incentives in a National Face-to-face Survey: Do They Affect Response Quality?, in: Field Methods, Vol. 28(3), 266-283.

Groves, Robert M. (2006), Nonresponse Rates and Nonresponse Bias in Household Surveys: What Do We Know about the Linkage between Nonresponse Rates and Nonresponse Bias?, in: Public Opinion Quarterly, Vol. 70(5), 646-675.

Groves, Robert M./Robert B. Cialdini/Mick P. Couper (1992), Understanding the Decision to Participate in a Survey, in: The Public Opinion Quarterly, Vol. 56(4), 475-495.

Groves, Robert M./Floyd J. Fowler Jr/Mick P. Couper/James M. Lepkowski/Eleanor Singer/Roger Tourangeau (2009), Survey Methodology, New Jersey: Wiley.

Groves, Robert M./Eleanor Singer/Amy Corning (2000), Leverage-Saliency Theory of Survey Participation: Description and an Illustration, in: The Public Opinion Quarterly, Vol.64(3), 299-308.

Gumprecht, Daniela (2010), Effekte der Erhebungsmethode im österreichischen Mikrozensus, in: Austrian Journal of Statistics, Vol. 39(I/2), I27-I37.
Habich, Roland (2OII), Soziale Lagen und soziale Schichtung, in: Statistisches Bundesamt (Destatis)/Wissenschaftszentrum Berlin für Sozialforschung (in Zusammenarbeit mit dem Sozio-ökonomischen Panel (SOEP) am Deutschen Institut für Wirtschaftsforschung) (ed.), Datenreport 20II, Bonn: Bundeszentrale für politische Bildung, I73-I79.

Haslinger, Alois/Josef Kytir (2006), Stichprobendesign, Stichprobenziehung und Hochrechnung des Mikrozensus ab 2004, in: Statistische Nachrichten, Vol. 2006(6), 510-519.

Hradil, Stefan (2OI2), Soziale Milieus und Lebensstile, in: Bulletin der Schweizerischen Akademie der Geistes- und Sozialwissenschaften, Vol. 20I2(4), 40-43.

Kennedy, John M./Judith A. Ouimet (2014), The Effect of Incentives on Internet Surveys: Response Rate Changes After the Introduction of Incentives, in: Asian Journal for Public Opinion Research, Vol. I(2), I28-I46.

Kronauer, Martin (2008). Ausgrenzung und physischsozialer Raum. In Sozialer Ausschluss und Soziale Arbeit, I8I-98. Wiesbaden: VS Verlag für Sozialwissenschaften.

Kytir, Josef/Bettina Stadler (2004), Die kontinuierliche Arbeitskräfteerhebung im Rahmen des neuen Mikrozensus, in: Statistische Nachrichten, Vol. 2004(6), $5 \mathrm{II}-52 \mathrm{O}$.

Laurie, Heather/Peter J. Lynn (2009), The Use of Respondent Incentives on Longitudinal Surveys, in: Lynn, Peter J. (ed.), Methodology of Longitudinal Surveys, West Sussex: Wiley, 205-233.

Lawler, Edward J. (200I), An Affect Theory of Social Exchange, in: American Journal of Sociology, Vol. IO7(2), 32I-352.

Leeuw, Edith D./Mario Callegaro/Joop Hox/Elly Korendijk/ Gerty Lensvelt-Mulders (2007), The Influence of Advance Letters on Response in Telephone Surveys a Meta-Analysis, in: Public Opinion Quarterly, Vol. 7I(3), 4I3-443.

Medway, Rebecca L./Roger Tourangeau (2015), Response Quality in Telephone Surveys: Do Prepaid Cash Incentives Make a Difference?, in: Public Opinion Quarterly, Vol. 79(2), 524-543.

Meraner, Angelika/Daniela Gumprecht/Alexander Kowarik (2016), Weighting Procedure of the Austrian Micro Census using Administrative Data, in: Austrian Journal of Statistics, Vol. 45(3), 3-I4.

Messer, Benjamin L./Don A. Dillman (20II), Surveying the General Public over the Internet Using AddressBased Sampling and Mail Contact Procedures, in: Public Opinion Quarterly, Vol. 75(3), 429-457.

Molm, Linda D./Jessica L. Collett/David R. Schaefer (2007), Building Solidarity through Generalized Exchange: A Theory of Reciprocity, in: American Journal of Sociology, Vol. II3(I), 205-242. 
Petrolia, Daniel R./Sanjoy Bhattacharjee (2009), Revisiting Incentive Effects: Evidence from a Random-Sample Mail Survey on Consumer Preferences for Fuel Ethanol, in: The Public Opinion Quarterly, Vol. 73, 537-550.

Pforr, Klaus/Michael Blohm/Annelies G. Blom/Barbara Erdel/Barbara Felderer/Mathis Fräßdorf/Kristin Hajek/ Susanne Helmschrott/Corinna Kleinert/Achim Koch/ Ulrich Krieger/Martin Kroh/Silke Martin/Denise Saßenroth/Claudia Schmiedeberg/Eva-Maria Trüdinger/ Beatrice Rammstedt (2015), Are Incentive Effects on Response Rates and Nonresponse Bias in Largescale, Face-to-face Surveys Generalizable to Germany? Evidence from Ten Experiments, in: Public Opinion Quarterly, Vol. 79(3), 740-768.

$R$ Core Team (2018), R: A Language and Environment for Statistical Computing, R Foundation for Statistical Computing, Vienna, Austria, Internet: https:// www.R-project.org/ (Acess: II.04.20I8).

Seymer, Alexander (20I7), Evaluierung und Dokumentation der Rekrutierungsexperimente bei der PUMAErhebung Q2/20I6, Report: PUMA/Statisitk Austria.

Scherpenzeel, Annette/Vera Toepoel (2012), Recruiting a Probability Sample for an Online Panel: Effects of Contact Mode, Incentives, and Information, in: Public Opinion Quarterly, Vol. 76(3), 470-490.

Shih, Tse H./Xitao Fan (2009), Comparing Response Rates in E-Mail and Paper Surveys: A Meta-Analysis, in: Educational Research Review, Vol. 4(I), 26-40.

Schupp, Jürgen/Christof Wolf (2015), Nonresponse Bias: Qualitätssicherung sozialwissenschaftlicher Umfragen, Wiesbaden: Springer Fachmedien.

Singer, Eleanor (20II), Toward a Benefit-Cost Theory of Survey Participation: Evidence, Further Tests, and Implications, in: Journal of Official Statistics, Vol. 27(2), 379-392.

Singer, Eleanor/Cong Ye (2OI3), The Use and Effects of Incentives in Surveys, in: The ANNALS of the American Academy of Political and Social Science, Vol. 645(I), II2I4I.

Vester, Michael/Peter Von Oertzen/Heiko Geiling/Thomas Hermann/Dagmar Müller (200I), Soziale Milieus im gesellschaftlichen Strukturwandel: Zwischen Integration und Ausgrenzung, Frankfurt am Main: Suhrkamp.

Warriner, Goyder K./Susan Miller (2002), Evaluating socio-economic status (SES) bias in survey nonresponse, in: Journal of Official Statistics, Vol. I8(I), I-II.

Wright, Erik O. (2005), Approaches to Class Analysis, New York: Cambridge University Press.

\section{Authors}

Dr. Alexander Seymer is Senior Lecturer at the Department of Sociology and Cultural Sociology at the University of Salzburg. He received his doctorate in 2013 from the University of Salzburg on the subject of values and political attitudes in the European Union. His research interests include research on values and attitudes, political sociology, quantitative methods of the social sciences and in particular the application of latent variables.

Dr. Martin Weichbold is a university professor for sociology and empirical social research at the University of Salzburg. After studying sociology, political science and psychology and his habilitation on computer-assisted forms of questioning, he is particularly concerned with quality criteria of social research, intercultural comparison and methodological and methodological questions of data construction. 